\title{
Avanços metodológicos na seleção do sexo de espermatozóides bovinos para utilização no melhoramento genético e na produção animal
}

\author{
Vera Fernanda Martins Hossepian de Lima ${ }^{1}$
}

1 - Departamento de Medicina Veterinária Preventiva e Reprodução Animal.14.884-940. Unesp/FCAV, Câmpus de Jaboticabal-SP, Brasil.veralima@fcav.unesp.br

RESUMO - O mercado demanda, desde final da década de 20, uma tecnologia para a sexagem de espermatozóides que possa ser inserida na indústria de produção de sêmen congelado e que tenha as seguintes características: a) não altere a viabilidade espermática; b) seja compatível com a congelação do espermatozóide sexado; c) permita a sexagem de espermatozóides previamente congelados e descongelados; d) permita a produção de várias doses de sêmen sexado congelado por dia, com custo compatível ao mercado. A importância dessa tecnologia para maximizar a produção animal a um custo baixo tem sido um desafio da pesquisa a vários anos. A possibilidade de produzir, em escala comercial, doses de sêmen enriquecidas com espermatozóides X ou Y aumentará os benefícios do uso da inseminação artificial no seu papel de maximizar o progresso genético entre gerações de acordo com os requerimentos de cada programa de melhoramento animal. Diferentes rotas tecnológicas são percorridas na tentativa de selecionar-se o sexo em mamíferos, tanto nas espécies de interesse zootécnico quanto em espécies ameaçadas de extinção, animais de companhia. Neste sentido, existem duas alternativas: a separação de espermatozóides portadores do cromossomo X, daqueles portadores do cromossomo Y; ou a sexagem de embriões pré-implantados. A viabilidade da sexagem de espermatozóides em bovinos é esperada por muitos anos e os desenvolvimentos recentes tornaram essa tecnologia de aplicação commercial. Entretanto, muitas limitações ainda existem, principalmente, referente à taxa de gestação em condições de campo. Isso restringe a utilização dessa tecnologia no melhoramento genético e produção animal. Nessa palestra abordaremos os potenciais sistemas de criação e produção que poderão beneficiar-se com a sexagem de espermatozóides, quando essas limitações forem solucionadas.

Palavras-chave: bovino, espermatozóides, seleção do sexo

\section{Methodological advances on spermatozoa sexing for using in genetic improvement and animal production}

\footnotetext{
ABSTRACT - The market demands, since the end of the 1920s the market demands a technology for spermatozoa sexing that can be inserted in the industry to production of frozen semen and that has the following features: a) does not change sperm viability; b) it be compatible with freezing of spermatozoa after treatment for sexing; c) it allows the spermatozoa sexing after their thawing; $d$ ) it allows the production of various doses of sexed frozen semen per day at a compatible cost for the market. The importance of this technology to maximize animal production at lower cost is a challenge of the research and it has been studied for many years. The possibility to produce, in commercial scale, semen doses enriched with X or Y spermatozoa will increase the benefits of the use of artificial insemination (AI) for its decisive role to maximize the genetic progress between generations, according to the requirements of each genetic improvement program and livestock capacity. Different technological routes are taken in the attempt to select gender in mammals, both for zootechnical interest species and for endangered species and pet animals. There are two alternatives for that: to separate X-chromosome-bearing spermatozoa from those Y- chromosome-bearing spermatozoa; or to sex pre-implanted embryos.The availability of sexed semen in cattle has been eagerly anticipated for many years, and recent developments have brought this technology to the brink of commercial application. Limitations still exist, namely conception rates in field. This limits the willingness of producers to pay a premium price for the product. The focus of this paper is to discuss potential breeding schemes that can lead to widespread usage of sexed semen, in spite of its aforementioned limitations.
}

Key Word: bovine, spermatozoa, sex selection 


\section{Introdução}

Diferentes rotas tecnológicas são percorridas na tentativa de selecionar-se o sexo em mamíferos, tanto nas espécies de interesse zootécnico quanto em espécies ameaçadas de extinção, animais de companhia e na reprodução humana assistida. Neste sentido, existem duas alternativas: a separação de espermatozóides portadores do cromossomo $\mathrm{X}$, daqueles portadores do cromossomo $\mathrm{Y}$; ou a sexagem de embriões pré-implantados.

O mercado demanda, desde final da década de 20, uma tecnologia para a sexagem de espermatozóides que possa ser inserida na indústria de produção de sêmen congelado. Desta forma, tal invento não altera a viabilidade espermática a índices inferiores àqueles recomendados pelos órgãos de fiscalização (por exemplo, Ministério da Agricultura); é compatível com a congelação dos espermatozóides após o tratamento para sexagem; permite a sexagem de espermatozóides após o descongela-mento dos mesmos; e permite a produção de várias doses de sêmen sexado (com acuidade de até $85 \%$ ) congelado por dia a um custo compatível com o mercado.

A importância dessa tecnologia é a sua utilidade para maximizar produção animal com menor custo e vem sendo estudada durante vários anos. A possibilidade de produzir, em escala comercial, doses de sêmen enriquecido com espermatozóides portadores do cromossomo $\mathrm{X}$ ou $\mathrm{Y}$, aumentará os benefícios da utilização da inseminação artificial (IA), conferindo-lhe um papel relevante na maximização do progresso gené-tico entre gerações, de acordo com as necessidades de cada programa de melhoramento genético e da aptidão do rebanho.

\section{Produção de leite}

Um exemplo são as raças especializadas para a produção de leite, nas quais a manutenção de gestações e o nascimento de animais do sexo masculino é um dos fatores de diminuição da produtividade e aumento dos custos de produção. $\mathrm{O}$ progresso genético será maximizado em programas de criação para a produção de leite em que a proporção sexual é controlada por ocasião da inseminação artificial, obtendo-se machos ou fêmeas, quando desejado (van Vleck et al., 1976).
Van Vleck (1981) e Dematawewa \& Berger (1998) estimaram um custo aproximado de US\$19US $\$ 35,00$ por unidade de sêmen. Atualmente, cerca de 150-200 doses de sêmen enriquecidas com espermatozóides $\mathrm{X}$ podem ser produzidas por citômetro por dia e isso compreende menos que $0,5 \%$ das necessidades diárias de doses de sêmen do mercado dos Estados Unidos. Além disso, a taxa de prenhez de novilhas a campo está em torno de $35-40 \%$ e $55-60 \%$ utilizando sêmen sexado e convencional, respectivamente. Está baixa taxa (35-40\%) é o fator limitante para a utilização do sêmen sexado naquele país (Weigel, 2004).

Nos rebanhos de elite, conseguiu-se um progresso genético mais modesto do que aquele predito anteriormente (Weigel, 2004). O autor sugere que a habilidade de alterar a proporção sexual da progênie de touros e vacas de elite tem menor impacto no ganho genético anual, que é aumentado em torno de 0,4 a $1,4 \%$, mesmo quando associado a múltiplas ovulações e transferência de embriões (Weigel, 2004). Entretanto, o autor referiu-se a estimativas que a seleção do sexo teria um efeito maior nos rebanhos comerciais de produção de leite, particularmente naquelas situações onde o macho tem valor econômico mínimo ou negativo. Além disso, o uso de seleção do sexo na produção in vitro de embriões (PIV) minimizaria o custo do teste de progênie em cerca de $33 \%$ já que permitiria apenas a transferência dos embriões do sexo desejado (Nicholas, 1996).

\section{Produção de carne}

Nos programas de cruzamento industrial a seleção do sexo de espermatozóides maximizará a produtividade e permitirá obter-se maior proporção de machos (75-90\%) em relação às fêmeas (10-25 \%) (Hohenboken, 1999). Devido às diferenças entre os sexos nas características de carcaça - o peso morto do macho, aos 24 meses é cerca de $25 \%$ maior que o peso morto da fêmea da mesma idade - o valor de uma progênie com $100 \%$ de machos será cerca de $34 \%$ maior do que aquela composta de $40 \%$ de machos (Ruvuna et al., 1992). Entretanto, existem programas de cruzamento que são beneficiados pelo nascimento de maior proporção de fêmeas na primeira geração (F1). Essas fêmeas são utilizadas como matrizes, ou seja, inseminadas com touros de raças ter- 
minais (com características de carcaça e conversão alimentar), o que possibilita maior rendimento na produção de carne após o abate (Hohenboken, 1999). Esses programas assemelham-se àqueles sistemas de produção de carne com raças puras, nos quais a máxima produtividade é obtida quando toda a progênie é do sexo feminino (Taylor, 1986).

Em sistemas de produção de carne utilizandose raças puras, a conversão alimentar da matriz é inversamente proporcional ao número de bezerros que compõe a sua progênie. Assim, no sistema de produção de carne, a máxima eficiência é alcançada quando a fêmea é acasalada quando novilha produz uma fêmea que a reporá no rebanho e é abatida logo após a desmama da mesma (singlesex bred heifer ou $\mathrm{SSBH}$ ). As razões são as seguintes:

a) nesta idade a matriz assume o papel do produto no abate, o que minimizará o custo de produção do bezerro;

b) quanto maior o número de parições menor a conversão alimentar da fêmea.

Com o controle do sexo, por sexagem dos espermatozóides ou embriões, cada matriz poderá produzir uma bezerra, ou várias (pela indução de múltiplas ovulações), na primeira gestação e então, ser abatida após a desmama deste produto (Taylor, 1986; Hohenboken, 1999).

Na população de elite, comparou-se a resposta de seleção entre um rebanho fechado e submetido a programas de múltiplas ovulações e transferência de embriões (MOTE) seria melhorado pelo aumento da proporção de novilhas de $50 \%$ para $67 \%$ ou $75 \%$. Como rebanho era fechado, a intensidade de seleção das fêmeas aumentou. Concomitantemente, houve uma diminuição na intensidade de seleção dos machos e nenhum benefício líquido com a seleção do sexo (Hohenboken, 1999). Assim, como predito, em uma população fechada, o controle da proporção sexual na progênie tem pouco efeito nas taxas de resposta seleção devido à manipulação das intensidades de seleção de machos ou fêmeas (Hohenboken, 1999).

\section{Perspectivas para a aplicação comercial da sexagem de espermatozóides}

A aplicabilidade comercial da sexagem dos espermatozóides depende do estabelecimento de uma metodologia que além de ser compatível com o processo de congelação, minimize a perda de espermatozóides durante o processo e não reduza o poder fecundante dos mesmos. Considerando estes aspectos, é necessário avaliar a qualidade não somente em relação à acuidade de sexagem, mas também no que diz respeito à viabilidade dos espermatozóides após a descongelação das doses de sêmen enriquecidas com espermatozóides portadores do cromossomo X ou Y. Estes aspectos são decisivos para tornar factível a produção de doses de sêmen enriquecidas com espermatozóides $\mathrm{X}$ ou Y pela indústria da inseminação artificial a um custo compatível com a realidade do mercado.

Em bovinos, a IA pode ser considerada uma das técnicas responsáveis pelo incremento da produtividade. No Brasil, cerca de $7 \%$ das fêmeas em idade de reprodução são inseminadas (Associação Brasileira de Inseminação Artificial, 2005). O número crescente de rebanhos submetidos a programas de melhoramento genético e cruzamento industrial, que tem tido crescimento expressivo desde 1989, é que permitiu que a utilização da IA apresentasse um crescimento de $350 \%$ nos últimos 10 anos. Estes mesmos Programas é que permitem que, atualmente, as vendas de sêmen sustentem-se em patamar acima de sete milhões de doses por ano (Associação Brasileira de Inseminação Artificial, 2005). Além das vantagens zootécnicas (Hohenboken, 1999), este mercado crescente e potencial para IA é o que justifica o grande interesse na sexagem de espermatozóides por parte das empresas de colheita e comercialização de sêmen que operam no Brasil. Entretanto, a IA tanto no Brasil como no mundo está restrita a cerca de $5 \%$ e $1 \%$ do mercado considerando as fêmeas em idade de reprodução ou registradas, respectivamente (Hasler, 2003).

Várias técnicas descritas até o momento para separação de espermatozóides X ou Y envolvem procedimentos complicados com o uso de equipamentos sofisticados que ainda se encontram em processo de aperfeiçoamento para se adequarem à indústria de produção de sêmen, como é o caso do citômetro de fluxo. Além disso, todas estas técnicas, principalmente a citometria de fluxo, causam danos irreparáveis aos espermatozóides e ao seu DNA, comprometendo, portanto, a eficiência do espermatozóide no processo de 
fertilização e produção de embriões capazes de se desenvolver sem alterações no DNA.

Para selecionar o sexo de embriões bovinos, o mercado também é restrito já que o volume de transferências corresponde à cerca de $1 \%$ do total das vacas registradas no Brasil e em países como Estados Unidos e Canadá (Sociedade Brasileira de Tecnologia de Embriões, 2005; Hasler, 2003).

A separação dos espermatozóides porta-dores do cromossomo $\mathrm{X}$ daqueles portadores do $\mathrm{Y}$ baseia-se na detecção de pelo menos uma das seguintes diferenças fenotípicas (físicas ou químicas) entre esses dois tipos de células

Blecher et al. (1999) relataram a identificação e isolamento de proteínas específicas do sexo (SSP, Sex Specific Protein) para obtenção de anticorpos específicos do sexo masculino e do sexo feminino. Após a incubação com espermatozóides bovinos, os anticorpos antiproteínas específicas do sexo feminino promoveram a aglutinação de 50\% daquelas células. As células que não sofreram aglutinação produziram in vitro 106 embriões, dos quais apenas 72 puderam ser sexados por citogenética sendo $92 \%$ destes do sexo masculino. Não foi relatado se a incubação de espermatozóides com anticorpos antiproteínas macho específica também promoveu o desvio da proporção sexual em favor do sexo feminino. É importante ressaltar que, a validação do método foi por citogenética, sendo que cerca de $28 \%$ embriões não puderam ser sexados por esta técnica. Os autores postularam a presença de diferentes proteínas cromossomais específicas do sexo, na superfície dos espermatozóides X e Y, originárias de transcrição e tradução pós-meiótica e que não seriam capazes de atravessar as pontes interespermáticas. Os autores consideram que após um aprimoramento deste novo método seria possível desenvolver uma técnica imunológica de separação de espermatozóides portadores do cromossomo X e Y, apesar de estudos prévios (Hendriksen et al., 1999) reportarem insucesso no sentido de estabelecer diferenças de proteínas de membrana entre os espermatozóides X e Y.

Blecher (1999) registrou a identificação das moléculas específicas do sexo descrevendo as possíveis utilizações práticas do seu invento, relatando o desenvolvimento de um método para a sexagem imunológica dos espermatozóides, pela identificação de proteínas específicas do sexo
(SSP, Sex Specific Protein). Esses métodos baseiam-se na identificação e isolamento dessas proteínas, na sua purificação por cromatografia de coluna e na obtenção de anticorpos antiproteínas específicas do sexo masculino e do sexo feminino. Após a incubação com espermatozóides bovinos, os anticorpos antiproteínas específicas do sexo feminino promoveram a aglutinação de $50 \%$ daquelas células. As células que não sofreram aglutinação produziram in vitro $92 \%$ de embriões do sexo masculino. Não foi relatado se a incubação de espermatozóides com anticorpos antiproteínas macho específicas também promoveu o desvio da proporção sexual em favor do sexo feminino. Os autores postularam a presença de diferentes proteínas cromossomais específicas do sexo, na superfície dos espermatozóides X e Y, originárias de transcrição e tradução pós-meiótica e que não seriam capazes de atravessar as pontes interespermáticas.

Um aprimoramento deste método se faz necessário para sua aplicação em escala comercial e em programas de melhoramento genético e produção animal já que os autores não relatam o desvio da proporção sexual em favor do sexo feminino, o qual é preferido nestes programas. $\mathrm{O}$ autor afirma que o resultado preliminar da identificação destas moléculas poderia, no futuro ser utilizado em escala comercial para sexagem de espermatozóides por técnica imunológica.

A despeito da existência das patentes sobre sexagem de espermatozóides pelo método imunológico, estudos eletroforéticos da membrana dos espermatozóides $\mathrm{X}$ ou Y, separados por citometria de fluxo, têm demonstrado que não é possível identificar-se diferenças entre as proteínas de membrana dos portadores do cromossomo $\mathrm{X}$ ou Y (Hendriksen et al., 1999). A explicação poderia ser a existência de vários mecanismos biológicos para prevenir a expressão haplóide e a possível troca de mRNA devido à presença de pontes citoplasmáticas entre as espermátides $\mathrm{X}$ e Y (Ericksson et al., 1981).

A quantidade de DNA entre os cromossomos $\mathrm{X}$ e Y varia significativamente entre as espécies e, até o momento é a única diferença estabelecida e validada cientificamente para a separação eficiente de espermatozóides $\mathrm{X}$ ou $\mathrm{Y}$ in vitro (Johnson et al., 1994). Em bovinos, esta diferença no conteúdo de DNA chega à cerca de 4,0 \% (Garner et al., 
1983; Johnson, 1994; Garner, 2006). Com base nesta diferença, existem duas técnicas que podem ser utilizadas para a seleção do sexo dos espermatozóides: a citometria de fluxo e a centrifugação em gradiente de densidade.

A diferença entre a quantidade de DNA dos espermatozóides $\mathrm{X}$ ou Y é evidenciada utilizandose um corante fluorescente. Após a coloração, os espermatozóides X ou Y são separados de acordo com a intensidade de fluorescência em um citômetro de fluxo (Johnson \&Welch, 1999).

As primeiras publicações sobre a sexagem de espermatozóides bovinos utilizando citometria de fluxo relatavam acuidade de $90 \%$ quando a velocidade do fluxo é de cerca de 100 células por segundo, o que corresponde a aproximadamente $2 \times 10^{6}$ espermatozóides a cada 5-6 horas. Naquela época, eram necessárias cerca de 30 horas para separar a quantidade de espermatozóides necessária para produzir uma dose de sêmen congelado para inseminação artificial por via cervical, que é a via utilizada convencionalmente (Johnson et al., 1994; Seidel et al., 1996). No entanto, durante os últimos anos muitos estudos foram efetuados no sentido de otimizar os resultados obtidos com esta técnica. Alguns aspectos foram substancialmente modificados com o objetivo de vencer as limitações da técnica. Por exemplo, a variabilidade ou heterogeneidade do sinal de fluorescência dos espermatozóides devido à pequena variação de DNA (3 a 4\%), nas distintas espécies de mamíferos, nos cromossomos $\mathrm{X}$ ou $\mathrm{Y}$, a qual é superada pelo uso de um novo sistema orientado por um funil. Este novo sistema, aliado ao uso de um equipamento separador de células com elevada velocidade, promoveu a separação de mais de 11 milhões de espermatozóides portadores do cromossomo X por hora, com 85 a $90 \%$ de pureza (Johnson \& Welch, 1999).

Neste sentido, vale lembrar que a pureza dos espermatozóides separados pela citometria de fluxo pode ficar em torno de $85 \%$ quando a velocidade de separação de apenas uma das subpopulações é de 11 milhões/hora. Entretanto, quando essa velocidade de fluxo é aumentada para 18 milhões/hora a pureza dos espermatozóides diminui para $75 \%$ (Johnson \& Welch, 1999).

Entre os fatores que ainda limitam a eficiência desta técnica destacam-se, principalmente, o baixo número de espermatozóides sexados viáveis; a longa exposição ao corante tóxico sob alta temperatura e a necessidade de utilizar sêmen in natura (Johnson et al., 1994).

Com o aumento da eficiência dos protocolos de fecundação in vitro poucos espermatozóides são necessários para fecundar um oócito. Assim, a probabilidade do emprego desta técnica é maior. Em bovinos, utilizando-se 5 a 10 mil espermatozóides sexados/oócito é possível, por citometria de fluxo, separar-se por hora espermatozóides X suficientes para se fecundar até 2200 oócitos. Entretanto, utilizando espermatozóides sexados, sem submetê-los a congelação, obtém-se índice de apenas $66 \%$ de clivagem, 16 a $20 \%$ de desenvolvimento (Lu et al., 1999; Guthrie et al., 2002). A utilização de espermatozóides sexado congelado poderá reduzir drasticamente estas taxas.

Jonhson (2000) destaca que a capacitação prematura é claramente uma característica do espermatozóide sexado pelo citômetro, o que é uma desvantagem para o espermatozóide que será destinado a estocagem (congelação), mas é uma vantagem para o espermatozóide que será usado imediatamente após a separação para fazer FIV, dispensando a indução da capacitação dos espermatozóides antes da fertilização.

Outra limitação é a diminuição da eficiência de sexagem de espermatozóides descongelados, devido ao fato da congelação prejudicar a uniformidade da coloração dos núcleos, com o corante Hoechst 33342 (Johnson et al., 1994). Isto restringe a utilização dos melhores touros (touros provados), dentro de cada raça, nos programas de melhoramento animal e teste de progênie que utilizam a produção in vitro de embriões.

Apesar dos tratamentos utilizados no método de citometria de fluxo (coloração com Hoechst 33342 e exposição à luz ultravioleta) aparentemente não impedirem o desenvolvimento in vitro do zigoto, Libbus et al. (1987) observaram aberrações cromossômicas em 50 \% dos espermatozóides de Microtus oregoni, após a sexagem por esse método. A frequiência das quebras, por exemplo, foi de 0,6 e 2,9 no grupo controle e naquele que recebeu o tratamento, respectivamente. $\mathrm{O}$ número total de aberrações por célula chegou a 7,5.

Além disso, em bovinos a motilidade de espermatozóides sexados por essa técnica foi de apenas $51 \%$ para as frações X ou Y (Johnson \& 
Welch, 1999). Após o processo de congelação e descongelação a motilidade diminuiu para $45 \%$ (laser regulado para $100 \mathrm{~mW}$; 351, $364 \mathrm{~nm}$ ) e apenas $65 \%$ dos espermatozóides sexados mantiveram a integridade do acrossoma (Schenk et al., 1999).

Esses espermatozóides descongelados (1 a 3 milhões/dose) quando depositados no corpo e nos cornos do útero de novilhas produziram um índice de prenhez médio de $48,5 \%$ e $50,5 \%$, respectivamente. Neste trabalho, foram obtidas 108 prenhezes utilizando espermatozóides congelados portadores do cromossomo $\mathrm{X}$ em IA no corpo ou cornos uterinos, das quais $88(81,5 \%)$ eram de fetos do sexo feminino, conforme diagnóstico por ultra-sonografia (Seidel \& Johnson, 1999). Esses fatores, associados ao pequeno número de células separadas por hora, dificultam a aplicação comercial desta técnica e incentivam a investigação de outra diferença fenotípica entre os espermatozóides X e Y que possa ser discriminada por citometria de fluxo. Um exemplo é o trabalho de van Munster et al. (1999 a,b) que confirmaram a existência de diferença no volume da cabeça entre os espermatozóides $\mathrm{X}$ ou $\mathrm{Y}$ e a propuseram como um parâmetro alternativo para sexagem por citometria de fluxo. Entretanto, os autores ainda não descreveram as modificações que serão necessárias no citômetro de fluxo, para viabilizar a sexagem utilizando esse parâmetro. Além disso, não há garantia de que este novo sistema mantenha a viabilidade espermática durante o processo, já que outros fatores ainda não quantificados podem prejudicar essa viabilidade, tais como:

a) a velocidade em que o fluxo de espermatozóides passa pelo citômetro;

b) a temperatura na qual os espermatozóides são mantidos durante o processo;

c) o tempo gasto durante o processo para separação dos espermatozóides.

Apesar da necessidade de uso de doses de sêmen com baixíssima quantidade de espermatozóides (compatível com a produção do citômetro) e da baixa viabilidade espermática pós sexagem, a citometria de fluxo tem sido o método mais estudado por vários grupos nos últimos vinte anos devido, principalmente, a acuidade de sexagem que pode atingir até 95\% (Garner, 2000). Entretanto, a revisão da literatura denota que os resultados de fertilidade a campo utilizando os espermatozóides sexados por este método demonstram índices favoráveis em condições experimentais e estritamente controladas. Espermatozóides descongelados (1 a 3 milhões/dose) quando depositados no corpo do útero de novilhas produziram um índice de prenhez médio de 48,5\% e $50,5 \%$ quando depositados nos cornos uterinos (Seidel et al., 1999). Neste trabalho foram obtidas 108 prenhezes utilizando espermatozóides congelados portadores do cromossomo $\mathrm{X}$ em IA no corpo ou cornos uterinos, das quais $88(81,5 \%)$ eram de fetos do sexo feminino, conforme diagnóstico por ultra-sonografia (Seidel \& Johnson, 1999).

Nos Estados Unidos, resultados de um teste de campo compararam as taxas de prenhez, conseguidas com espermatozóides sexados por citometria de fluxo, em rebanhos com baixa, media e alta eficiência reprodutiva. A taxa média de prenhez utilizando doses de sêmen convencional foi de $58 \%$, enquanto que utilizando sêmen com espermatozóides sexados nesses rebanhos as taxas de gestação foram 21, 37, e 35\%, respectivamente. Considerando esses resultados, torna-se evidente que os espermatozóides sexados por citometria de fluxo comprometem a taxa de gestação, pelo menos atualmente, e estratégias para a aplicação comercial in vivo desse sêmen deveriam ter como foco caminhos para se obter um benefício efetivo, incluindo a idade a primeira parição, frente ao custo de utilização (Weigel, 2004).

Na Finlândia, outro teste de campo (em uma cooperativa de produção de leite) comparou as taxas de prenhez, conseguidas com espermatozóides sexados por citometria de fluxo (foram utilizadas 157 doses) e com sêmen convencional (foram utilizadas 149 doses). A taxa média de prenhez utilizando doses de sêmen convencional foi de $46 \%$, enquanto que utilizando sêmen com espermatozóides sexados nesses rebanhos a taxa de gestação foi $21 \%$, respectivamente. Assim nasceram mais bezerras após a IA com sêmen convencional (33 bezerras) do que como sêmen sexado (27 bezerras) (Andersson et al., 2006). Considerando esses resultados, torna-se evidente que os espermatozóides sexados por citometria de fluxo comprometem a taxa de gestação, pelo menos atualmente, e estratégias para a aplicação comercial in vivo desse sêmen deveriam ter como 
foco caminhos para se obter um benefício efetivo, incluindo a idade a primeira parição, frente ao custo de utilização (Weigel, 2004).

A citometria de fluxo é considerada por alguns autores a técnica mais promissora, devido à acuidade de separação estar em torno de $90 \%$. Entretanto, ela tem se demonstrado altamente dispendiosa, e a capacidade de fecundação dos espermatozóides é significativamente reduzida (Cran et al., 1995).

Para exemplificar, há dados da literatura (Johnson \& Welch, 1999) que demonstram que, por citometria de fluxo, é necessária uma hora para se produzir 18 milhões de espermatozóides sexados com pureza de $75 \%$ e com viabilidade comprometida após descongelação na maioria das vezes. Utilizando a centrifugação em gradiente de densidade conseguiu-se produzir no mesmo período de tempo pelo menos 450 milhões de espermatozóides sexados com pureza de até $81 \%$ e mantendo-se a viabilidade espermática em índices comparáveis ao sêmen não sexado (Hossepian de Lima et al., 2003).

Os procedimentos envolvendo sedimen-tação ou centrifugação de espermatozóides baseiam-se na diferença de densidade existente entre os portadores do cromossomo X ou Y. Sumner \& Robinson (1976) analisaram por microinterferometria a cabeça dos espermatozóides e verificaram que os portadores do cromossomo X contêm mais DNA e proteína nuclear que os espermatozóides $\mathrm{Y}$ e que esta diferença é proporcional à diferença de massa entre os dois tipos de células. A análise de espermatozóides $\mathrm{X}$ ou $\mathrm{Y}$ de várias espécies por mensuração das cromátides (Moruzzi, 1979) ou por citometria de fluxo (Garner et al., 1983; Garner, 2006) revelaram que a diferença no conteúdo de DNA varia de $2,8 \%$ na espécie humana a 12,5\% no Microtus oregoni (Johnson \& Clarke, 1990). Nos animais domésticos, as diferenças de DNA entre os espermatozóides $\mathrm{X}$ ou Y variam de $3,5 \%$ a $4,2 \%$, sendo que nos bovinos ela é de cerca de 4,0\% (Garner et al., 1983; Johnson et al., 1994; Garner, 2006). Nesta espécie, observou-se uma diferença média significativa do conteúdo de DNA dos espermatozóides $\mathrm{X}$ ou $\mathrm{Y}$ entre as raças, mas não entre os indivíduos da mesma raça. Entre os espermatozóides $\mathrm{X}$ ou Y de touros Jersey observou-se a maior diferença $(4,24 \%)$ quando comparada com as raças Angus
(4,05\%), Hereford (4,03\%), Holstein (3,98\%) e Brahman $(3,73 \%)$ que apresenta a menor diferença. A grande quantidade de água e de lipídeos contida na cabeça dos espermatozóides, já que o DNA corresponde a apenas $18 \%$ da massa fazem com que a diferença do conteúdo de DNA produza uma pequena diferença no peso e, conseqüentemente, na densidade. Em 1982, Meistrich estimou que a diferença no conteúdo de DNA dos espermatozóides $\mathrm{X}$ ou Y de bovinos resulta em uma diferença de densidade de $7 \times 10^{-4}$ $\mathrm{g} / \mathrm{cm}^{3}$, ou $0,06 \%$ da densidade em relação a um espermatozóide X. O autor salientou que esta diferença faz com que a separação dos dois tipos de espermatozóides seja possível desde que se utilizem gradientes com alta resolução de densidade.

Em bovinos, Blottner et al. (1993) utilizaram centrifugação em gradiente de Percoll para a separação dos espermatozóides bovinos portadores do cromossomo X ou Y. O gradiente consistiu de 10 camadas de $0,6 \mathrm{ml}$ de soluções de Percoll com concentrações variando entre $22 \%$ e $48 \%$. Este método propiciou um enriquecimento de mais de $75 \%$ de espermatozóides $\mathrm{X}$ ou $\mathrm{Y}$ nas frações inferiores e superiores, respectivamente, como verificado por hibridização in situ. Após as duas centrifugações, os espermatozóides de ambas frações não demonstraram nenhuma diferença significativa quanto à morfologia. A indução da reação acrossômica demonstrou capacitação normal. Os espermatozóides de ambas frações foram utilizados para produção in vitro de embriões que foram sexados por PCR, o que demonstrou que a utilização de espermatozóides da fração superior e inferior resultaram em $75 \%$ e $92 \%$ de embriões do sexo masculino e feminino, respectivamente.

Recentemente, Hossepian de Lima et al. (2003) descreveram em patente gradientes compostos de soluções isotônicas feitas a partir de substâncias compostas de partículas coloidais ou gradientes feitos com soluções isotônicas a partir de componentes iodinatados que permitem em uma única centrifugação, separar as impurezas (partículas leves, espermatozóides imaturos, células, bactérias, etc) dos espermatozóides viáveis e, dentre estes, separar os espermatozóides X dos Y. A diminuição do número de centrifugações permite, sem alterar a acuidade de separação dos 
espermatozóides $\mathrm{X}$ e $\mathrm{Y}$, diminuir as injúrias causadas nos espermatozóides pelas sucessivas centrifugações e manipulações e assim preservar a resistência dos mesmos ao processo de congelação.

A introdução de componentes iodinatados (desenvolvidos para uso como contraste em procedimentos utilizando raios- $\mathrm{X}$ ) como meio para gradientes de densidade ofereceu novas oportunidades para melhorar os métodos de separação de material biológico, especialmente células e organelas subcelulares. O iodixanol é um componente iodinatado não iônico desenvolvido para estudos envolvendo raios- $\mathrm{X}$ e caracteriza-se por ser uma forma dimérica do Nycodenz e ter o dobro do seu peso molecular. Na separação de organelas subcelulares, o iodixanol apresenta vantagens sobre o Percoll e o Nycodenz, já que é denso o suficiente para produzir gradientes com densidades superiores a $1,32 \mathrm{~g} / \mathrm{ml}$ e com osmolaridade inferior a 300 mOsm (Graham et al., 1994).

A venda de sêmen previamente sexado é um evento tão esperado no mercado que vem sendo anunciado há alguns anos pelas indústrias do setor. Nenhuma dessas previsões foi concretizada já que a comercialização está restrita ao mercado local, com um pequeno número de doses produzidas por ano, muito aquém da demanda mundial. Além disso, as empresas afirmam que essas doses terão um baixo número de espermatozóides (nos testes foram utilizados $1-3 \times 10^{6}$ espermatozóides por dose) o que poderá inviabilizar a utilização deste método para produção de doses de sêmen destinadas a IA convencional. Provavelmente, a comercialização do sêmen sexado nesta concentração encontrará barreiras na legislação brasileira e de outros países que têm como número mínimo para comercialização $10 \times 10^{6}$ espermatozóides vivos viáveis por dose (Telford et al., 2003).

Estimativas da literatura científica demonstram que os métodos de sexagem de espermatozóides poderiam ter as seguintes vantagens para aumentar o progresso genético e produção animal:

- produzir doses de sêmen enriquecidas com espermatozóides portadores do cromossomo X ou Y por centrifugação em gradiente de densidade, em escala comercial, por um processo compatível com o processo de envase e congelação de sêmen existentes em empresas especializadas na produção e comercialização de sêmen congelado;

- não comprometer a capacidade fecundante dos espermatozóides;

- ser comercializada para utilização em programas de IA (Inseminação Artificial) utilizando a técnica tradicional (sêmen depositado logo após a cérvix) e em variadas condições de manejo reprodutivo, obtendose índice de prenhez e nascimentos de pelo menos $50 \%$ em bovinos de leite e $85 \%$ em bovinos de corte;

- ser utilizada em sêmen congelado após a descongelação, o que permite a utilização dos melhores touros (touros provados), dentro de cada raça, nos programas de melhoramento animal e testes de progênie que utilizam a produção in vitro de embriões, ao contrário da técnica por citometria, na qual a congelação e descongelação dos espermatozóides diminui a eficiência de sexagem devido ao fato da congelação prejudicar a uniformidade da coloração dos núcleos, com o corante Hoechst 33342;

- ser utilizada para PIV (Produção in vitro de embriões) obtendo-se índices de clivagem e desenvolvimento embrionário acima de $75 \%$ e $35 \%$, respectivamente;

- ter baixo investimento em equipamentos

A aplicabilidade comercial da sexagem dos espermatozóides depende do estabelecimento de uma metodologia que além de ser compatível com o processo de congelação, minimize a perda de espermatozóides durante o processo e não reduza o poder fecundante dos mesmos. Considerando estes aspectos, é necessário avaliar a qualidade não somente em relação à acuidade de sexagem, mas também no que diz respeito à viabilidade dos espermatozóides após a descongelação das doses de sêmen congelado enriquecidas com espermatozóides portadores do cromossomo $\mathrm{X}$ ou $\mathrm{Y}$.

Assim, é difícil concluir como seriam os resultados em países como o Brasil, que possuem uma pecuária caracterizada por heterogeneidade de condições de manejo. Neste sentido, considerase que para a realidade brasileira, é mais interessante optar-se por desenvolver uma metodologia de baixo custo, que atinja acuidade de sexagem 
em torno de $75 \%$, mas que permita, em condições variadas de manejo, obter-se índices de fertilidade satisfatórios.

O cenário da pecuária brasileira se comparado ao mundial permite prever que, no curto prazo, os criadores utilizarão os espermatozóides sexados nos procedimentos de PIV enquanto o retorno monetário obtido, com o bezerro do sexo desejado, exceder o custo de o produzir. Entretanto, no longo prazo, os criadores somente utilizarão os espermatozóides sexados se esse procedimento efetivamente maximizar o ganho genético anual e a produtividade. Além disso, caso a biossegurança seja negligenciada, no longo prazo a seleção do sexo poderá contribuir nesse sentido. Nos Estados Unidos, por exemplo, rebanhos comerciais e de elite tem expandido rapidamente em muitos estados, já que a pressão financeira leva muitos pecuaristas a buscar a economia em escala. Para essa expansão, os rebanhos fechados vêm utilizando a PIV e a seleção do sexo em matrizes do próprio rebanho e adquiridas em leilões, exposições agropecuárias ou de outros criadores. Quando essas matrizes ou as receptoras prenhez chegam, todos os animais da propriedade podem ser expostos a muitos novos patógenos (por exemplo, Leptospirose, Paratuberculose). A taxa de descarte involuntário subseqüente aumenta devido a maior frequiência de doenças, inabilidade das vacas se adaptarem e pobre potencial genético entre os animais comprados e seus descendentes (Weigel, 2004). Como resultado, os pecuaristas necessitam de mais animais de reposição, e o ciclo continua. Provavelmente, a possibilidade de utilização da seleção do sexo na PIV imporá aos técnicos o desafio de permitir que os criadores aumentem o número de fêmeas a partir de rebanhos fechados para evitar os problemas sanitários.

\section{Agradecimentos}

FAPESP, São Paulo, SP, Brasil pelo suporte financeiro para o dépósito da Patente BR PI 0300604-2, 17 Jun. 2003.

\section{Literatura citada}

ANDERSSON, M.; TAPONEN, J.; KOMMERI, M. et al. Pregnancy rates in lactating Holstein-Friesien cows after artificial insemination with sexed sperm. Reproduction Domestic Animals, v.41, p.95-7, 2006.
ASSOCIAÇÃO BRASILEIRA DE INSEMI-NAÇÃO ARTIFICIAL. Relatório Anual, São Paulo, p.4, 2005.

BLECHER, S.R.; HOWIE, R.; LI, S. et al. A new approach to immunological sexing sperm. Theriogenology, v.52, p.130922, 1999.

BLOTTNER, S.; SCHWERIN, M.; BÖTTCHER, M. et al. Selective enrichment of bovine $\mathrm{X}$ - and Y-spermatozoa by Percoll density gradient. Arch. Tierz., v.36, n.2, p.153-62, 1993.

CRAN, D.G.; JOHNSON, L.A.; POLGE, C. Sex preselection in cattle: a field trial. Veterinary Record, v.136, p.495-6, 1995.

DEMATAWEWA, C.M.B.; BERGER, P.J. Break-even cost of cloning in genetic improvement of dairy cattle. Journal of Dairy Science, v.81, n.4, p.1136-47, 1998.

ERICKSSON, R.P.; LEWIS, S.E.; BUTLEY, M. Is haploid gene expression possible for sperm antigen? Journal of Reproduction and Immunology, v.3, p.195-217, 1981.

GARNER, D.L.; GLEDHILL, L.; PINKEL, D. et al. Quantification of the X-and Y-chromosome-bearing spermatozoa of domestic animals by flow cytometry. Biology of Reproduction, v.28, p.312-21, 1983.

GARNER, D.L. Flow cytometric sexing of mammalian sperm. Theriogenology, v.65, p.943-957, 2006.

GARNER, D.L. Sex-Sorting mammalian sperm: concept to application in animals. Journal of Andrology, v.22, n.4, p.519-26, 2000.

GRAHAM, J.; FORD, T.; RICKWOOD, D. Analytical Biochemistry, v.220, p.367, 1994.

GUTHRIE, H.D.; JOHNSON, L.A.; GARRET, W.M. et al. Flow cytometric sperm sorting: Effects of varying laser power on embryo development in swine. Molecular Reproduction and Development, New York, v.61, n.1, p.87-92, 2002a

HASLER, J.F. The current status and future of commercial embryo transfer in cattle. Animal Reproduction Science, v.79, p.245-64, 2003

HENDRIKSEN, P.J.M. Do X and Y spermatozoa differ in proteins? Theriogenology, v.52, p.1295-1308, 1999.

HOHENBOKEN, W.D. Applications of sexed semen in cattle production. Theriogenology, v.52, p.1421-33, 1999.

HOSSEPIAN DE LIMA, V.F.M.; MOREIRA-FILHO, C.A.; RAMALHO, M.F.P.D.T. Processo de seleção do sexo de espermatozóides mamíferos e métodos de controle de qualidade de doses de sêmen sexado congelado. BR PI 0300604-2, 17 Jun. 2003.

JOHNSON, LA. Sexing mammalian sperm for production of offspring: the state-of-the-art. Animal Reproduction Science, v.60-61, p.93-107, 2000.

JOHNSON, L.A.; CLARKE, R.N. Sperm DNA and sex chromosome differences between two geographical populations of the creeping vole, Microtus oregoni. Molecular Reproduction and Development, v.27, p.15962, 1990.

JOHNSON, L.A.; CRAN, D.G.; POLGE, C. Recent advances in sex preselection of cattle: flow cytometric sorting of X- Ychromosome bearing sperm based on DNA to produce progeny. Theriogenology, v.41, n.1, p.51-6, 1994.

JOHNSON, L.A.; WELCH, G.R. Sex selection: high-speed flow cytometric sorting of $\mathrm{X}$ and $\mathrm{Y}$ sperm for maximum efficiency. Theriogenology, v.52, p.1323-1342, 1999.

LIBBUS, B.L.; PERREAULT, S.D.; JOHNSON, L.A. Incidence of Chromosome aberrations in mammalian sperm stained with HOESCHT 33342 and UV - laser irradiated during flow sorting. Mutation Research, v.182, p.265-274, 1987.

LU, K.H.; CRAN, D.G.; SEIDEL Jr., G.E. In vitro fertilization with flow-citometrically-sorted bovine sperm. Theriogenology, v.52, p.1393-1405, 1999.

MORUZZI, J.F. Selecting a mammalian species for the separation of X-and Y-chromosome-bearing spermatozoa. Journal of Reproduction and Fertility, v.57, p.319-23, 1979. 
NICHOLAS, F.W. Genetic improvement through reproductive technology. Animal Reproduction Science, v.42, p.205-14, 1996.

RUVUNA, F.; TAYLOR, J.F.; WALTER, J.P. et al. Bioeconomic evaluation of embryo transfer in beef production systems: III. Embryo lines production bulls. Journal of Animal Science, v.70, p.1091-97, 1992.

SCHENK, J.L.; SUH, T.K.; CRAN, D.G. et al. Cryopreservation of flow-sorted bovine spermatozoa. Theriogenology, v.52, n.8, p.1375-93, 1999.

SEIDEL Jr., G.E.; JOHNSON, L.A.; ALLEN, C.H. et al. Artificial insemination with X-and Y-bearing bovine sperm. Theriogenology, v.45, n.1, p.309, 1996.

SEIDEL Jr., G.E.; JOHNSON, L.A. Sexing mammalian sperm - overview. Theriogenology, v.52, n.8, p.1267-72, 1999.

SOCIEDADE BRASILEIRA DE TECNOLOGIA DE EMBRIÕES. A transferência de embriões no mundo. O EMBRIÃO, v.18, p.4-6, 2004.

SUMMER, A.T.; ROBINSON, J.A. A difference in dry mass between the heads of X-and Y-bearing human spermatozoa. Journal of Reproduction andfFertility, v.48, p.9-15, 1976. TAYLOR St., C.S., THIESSEN, R.B.; MOORE, A.J. Single sex beef cattle systems. In: SMITH, C., KING, J.W.B., McKAY, J.C.(Ed). Exploiting New Technologies in Animal Breeding, Oxford: Oxford University Press, 1986. p.183-93.
TELFORD, D.J.; BEARD, A.P.; FRANKS, J.R. The potential adoption and use of sexed semen in UK suckler beef production. Livestock Production Science, v.84, p.39-51, 2003.

VAN MUNSTER, E.B.; STAP, J.; HOEBE, R.A. et al Difference in volume of X- and Y-chromosome bearing bovine sperm heads matches difference in DNA content. Cytometry, v.35, p.125-8, 1999.

VAN MUNSTER, E.B.; STAP, J.; HOEBE, R.A. et al. Difference in sperm head volume as a theorical basis for a sorting X- and Y- bearing spermatozoa: a potentials and limitations. Theriogenology, v.52, p.1281-1293, 1999.

VAN VLECK, L.D. Potential genetic impact of artificial insemination, sex selection, embryo transfer, cloning and selfing in dairy cattle. In: BRACKETT, B.G., SEIDEL, G.E., SEIDEL, S.M. (Ed.). New technologies in animal breeding. Academic Press, 1981, p.221-42.

VAN VLECK, L.D.; EVERETT, R.W. Genetic valur of sexed semen to produce dairy heifers. Journal of Dairy Science, v.59, p.1802-07, 1976.

WEIGEL, K.A. Exploring the role of sexed semen in dairy production systems. Journal Dairy Science, v.87, (E. Suppl.): E120-E130, 2004. 